\title{
Nitric Oxide Production and Inducible Nitric Oxide Synthase Expression in Inflammatory Arthritides
}

\author{
Hiroshi Sakurai, ${ }^{\star}$ Hitoshi Kohsaka, ${ }^{*}$ Ming-Fei Liu, ${ }^{*}$ Hiroyuki Higashiyama, ${ }^{*}$ Yukio Hirata, ${ }^{\ddagger}$ Kazuo Kanno, ${ }^{\star}$ Ichiro Saito, ${ }^{\star}$ \\ and Nobuyuki Miyasaka* \\ *Division of Immunological Diseases, Medical Research Institute, ${ }^{\ddagger}$ Second Department of Internal Medicine, Tokyo Medical and Dental \\ University, Tokyo 113, Japan
}

\begin{abstract}
In this study, we have identified the source of nitric oxide (NO) produced in the human inflammatory joints by analyzing expression of inducible NO synthase. In ex vivo organ cultures, both inflammatory synovium and cartilage from patients with rheumatoid arthritis produced NO. The NO production was suppressed by $\boldsymbol{N}^{\mathbf{G}}$-monomethyl-L-arginine, an inhibitor of NO synthase. The amount of NO produced by the synovium correlated with the proportion of $\mathrm{CD}^{+}$ cells in the corresponding tissue $(r=0.8, P<0.05)$. Immunohistochemical analysis as well as in situ hybridization showed that inducible NO synthase was predominantly expressed in synovial lining cells, endothelial cells, chondrocytes, and to a lesser extent, in infiltrating mononuclear cells and synovial fibroblasts. The synovial lining cells and the infiltrating cells expressing inducible NO synthase were identified where $\mathrm{CD}^{+}$cells were located. Together with morphological features, this suggests that they are type $A$ synoviocytes. NO production from freshly isolated synoviocytes and chondrocytes was up-regulated by in vitro stimulation with a combination of IL-TNF- $\beta$, TNF- $\alpha$, and LPS.

In summary, the present results suggest that NO is produced primarily by $\mathrm{CD}^{+} 4^{+}$synoviocytes, chondrocytes, and endothelial cells in inflammatory joints of arthritides. NO production can be upregulated by cytokines present in inflamed joints. The increased NO production may thus contribute to the pathological features in inflammatory arthritides. (J. Clin. Invest. 1995. 96:2357-2363.) Key words: nitric oxide $\bullet$ inducible nitric oxide synthase $\bullet$ rheumatoid arthritis - synoviocyte $\cdot$ chondrocyte
\end{abstract}

\section{Introduction}

Nitric oxide (NO) is a short-lived, gaseous free radical, synthesized from L-arginine by NO synthases (NOS). ${ }^{1}$ NO has been

Address correspondence to Nobuyuki Miyasaka, First Department of Internal Medicine, Tokyo Medical and Dental University, 1-5-45 Yushima, Bunkyo-ku, Tokyo 113, Japan, which is his present address. Phone: 81-3-3813-6111; FAX: 81-3-5684-0057.

Received for publication 27 September 1994 and accepted in revised form 12 July 1995.

1. Abbreviations used in this paper: iNOS, inducible NOS; L-NMMA, $N^{\mathrm{G}}$-monomethyl-L-arginine; NOS, nitric oxide synthase; OA, osteoarthritis; RT, reverse transcriptase.

J. Clin. Invest.

(C) The American Society for Clinical Investigation, Inc.

0021-9738/95/11/2357/07 \$2.00

Volume 96, November 1995, 2357-2363 implicated as a mediator of immune and inflammatory responses.

Inflammatory mediators such as IL- 1, IFN- $\gamma$, TNF- $\alpha$, and LPS stimulate expression of the inducible isoform of NOS (iNOS) in rodent macrophages in vitro. The stimulated macrophages produce large amounts of NO for prolonged time periods (1). NO production and/or iNOS expression are also induced by inflammatory mediators in a wide variety of other mammalian cells, such as human and rodent hepatocytes and rodent smooth muscle cells (2-5).

Induced iNOS or NO expression have been observed in several rodent in vivo models of inflammatory diseases. iNOS mRNA was upregulated in the brain of mice with experimental autoimmune encephalomyelitis, and NO levels were increased in sera from rodents with rabies infection or graft-vs-host disease (6-8). NO production was increased in inflammatory synovium of rat arthritis induced by streptococcal cell-wall fragments, and elevated urinary NO excretion was seen in rat adjuvant arthritis. The onset of both forms of experimentally induced arthritis was blocked by the NOS inhibitor, $N^{\mathrm{G}}$-monomethyl-Larginine (L-NMMA) $(9,10)$. Furthermore, Weinberg et al (11) demonstrated that NO production and iNOS expression were increased in kidneys and spleens of MRL-lpr/lpr mice which develop murine lupus. The incidence of spontaneous arthritis and glomerulonephritis was reduced by orally administered L-NMMA.

RA is a chronic inflammatory disease of unknown etiology. The inflamed synovium in RA is characterized by marked hyperplasia of the synovial lining layers, neovascularization, and massive infiltration of leukocytes (12). In the synovial fluid and synovium, various cytokines derived from macrophages and/or fibroblasts, such as IL-1, IL-6, TNF- $\alpha$; and GM-CSF, are readily detected (13-16). In osteoarthritis (OA) synovium, the profile of cytokines produced is comparable with RA (17, 18). In addition to the cytokines, Farrell et al. (19) reported increased concentration of nitrite, which represents local NO production, in synovial fluids and sera from the patients with RA and OA.

Based on the these data, we speculated that NO and iNOS are involved in the inflammation of human arthritides. In this study, we have identified synoviocytes, endothelial cells, and chondrocytes as a major intraarticular source of NO and show that NO production can be upregulated by inflammatory cytokines present in the joints.

\section{Methods}

Patients. 15 patients ( 10 females, 5 males; mean age $57.3 \mathrm{yr}$ ) who fulfilled the American College of Rheumatology criteria for RA (20) and 11 patients ( 8 females, 3 males; mean age $70.4 \mathrm{yr}$ ) with OA were studied. The patients were taking $\leq 5 \mathrm{mg} / \mathrm{d}$ of prednisolone or $100 \mathrm{mg}$ / $\mathrm{d}$ of D-penicillamine. Four patients (4 males, mean age $59.0 \mathrm{yr}$ ) with 
trauma, which required surgical treatment, were also entered into the study.

Ex vivo organ culture of synovium and cartilage. The synovium obtained by synovectomy from the knee joints of RA patients was minced, and $50 \mathrm{mg}$ of the tissue were cultured in 48-well plates (Costar Corp., Cambridge, MA) in $0.5 \mathrm{ml}$ DME (GIBCO Laboratories, Grand Island, NY) containing 10\% FBS (GIBCO Laboratories), $100 \mathrm{U} / \mathrm{ml}$ penicillin, and $100 \mu \mathrm{g} / \mathrm{ml}$ streptomycin. In some of the cultures, 0.5 mM L-NMMA (Sigma Chemical Co., St. Louis, MO) was included to inhibit NOS activity.

Cartilage was collected during total knee replacement surgery of RA patients, and $50 \mathrm{mg}$ of tissue were cultured likewise.

Determination of nitrite concentration. The nitrite content of the supernatants, as an indicator of NO production, was assayed by the method of Ding et al. (21). In brief, $100 \mu$ l of Griess reagent was added to $100 \mu \mathrm{l}$ of the supernatant. The absorbance values were recorded with a plate reader at $540 \mathrm{~nm}$ (Molecular Devices, Menlo Park, CA). The nitrite concentration was determined by a standard curve generated with $\mathrm{NaNO}_{2}$. All assays were carried out in duplicate.

Flow cytometric analysis. Cells were isolated from the rheumatoid synovium as previously reported (16). In brief, minced synovium were treated with $0.5 \mathrm{mg} / \mathrm{ml}$ collagenase (Sigma) and $0.15 \mathrm{mg} / \mathrm{ml}$ DNase-I (Sigma) for $2 \mathrm{~h}$ at $37^{\circ} \mathrm{C}$. The isolated cells were incubated with FITClabeled anti-CD14 mAb (Coulter Immunology, Hialeah, FL). After three additional washes, $10^{4}$ cells were analyzed on a FACScan ${ }^{\circledR}$ flow cytometer (Becton Dickinson and Co., San Jose, CA).

Western blot analysis. Synoviocytes were isolated as described above. Chondrocytes were isolated by mincing rheumatoid cartilage as previously described (22). Minced cartilage was treated with $0.1 \%$ EDTA for $20 \mathrm{~min}$ at $37^{\circ} \mathrm{C}$, with $0.2 \%$ trypsin for $1 \mathrm{~h}$ at $37^{\circ} \mathrm{C}$, and with $0.2 \%$ collagenase for $2 \mathrm{~h}$ at $37^{\circ} \mathrm{C} .10^{6}$ chondrocytes were cultured in a 10-cm culture dish (Costar) in $5 \mathrm{ml}$ DME containing $10 \%$ FBS with a combination of $1 \mathrm{ng} / \mathrm{ml} \mathrm{IL-} \beta, 10 \mathrm{U} / \mathrm{ml} \mathrm{TNF}-\alpha$, (Asahi Chemical Industry Corporated Ltd., Osaka, Japan), and $10 \mu \mathrm{g} / \mathrm{ml}$ LPS (Escherichia coli O55:B5) (Sigma) for $48 \mathrm{~h}$.

These cells were lysed in buffer containing $1.0 \%$ NP-40 and $50 \mathrm{mM}$ Tris- $\mathrm{HCl}, \mathrm{pH} 8.0$, supplemented with a protease inhibitor $(2 \mathrm{mg} / \mathrm{ml}$ PMSF [Sigma]), and then centrifuged at $10,000 \mathrm{~g}$ for $5 \mathrm{~min}$ at $4^{\circ} \mathrm{C}$. Cytosolic protein ( $100 \mu \mathrm{g} /$ lane) was separated with $7.5 \%$ SDS-PAGE and transferred to nitrocellulose membranes. After overnight blocking in PBS with 3\% BSA and subsequent washing, the samples were immunoblotted with rabbit polyclonal anti-mouse iNOS antiserum (1:500). The anti-iNOS antiserum was generated by immunization of rabbits with an $\mathrm{NH}_{2}$-terminal peptide of mouse iNOS (23) and cross-reacted with human iNOS. Nonimmunized rabbit serum was used as a negative control. An alkaline phosphatase-conjugated anti-rabbit IgG antibody (GIBCO) was used as a second antibody. Positive signals were detected with 5-bromo-4-chloro-3-indolyl-phosphate and 4-nitroblue tetrazolium chloride (Boehringer Mannheim, Mannheim, Germany).

Immunohistochemical study. Fresh synovium and cartilage samples were frozen in optimal cutting temperature compound (Miles Laboratories Inc., Naperville, IL), and stored at $-80^{\circ} \mathrm{C}$ until used (24). The cryostat sections $(4 \mu \mathrm{m})$ on gelatin-coated slides were fixed in acetone and incubated with the rabbit polyclonal antiserum against iNOS or normal rabbit Ig as a negative control. The sections were then incubated with a biotinylated goat anti-rabbit IgG antibody (Vector Laboratories, Burlingame, CA) and an avidin-biotin immunoperoxidase (Vector Laboratories) and with $0.05 \% 3,3^{\prime}$-diaminobenzidine tetrahydrochloride (Sigma) and $0.03 \%$ hydrogen peroxide. They were counterstained with hematoxylin. For characterization of the cells expressing iNOS, the samples were stained with mAbs against CD2, CD14, CD20, HLA-DR (Coulter Immunology), or Factor VIII (Cedarlane Laboratories, Inc., Hornby, Canada).

In situ hybridization. The cryosections were mounted on poly-Llysine-treated glass slides and fixed in 4\% paraformaldehyde (25). Digoxigenin-labeled antisense riboprobes for human iNOS gene were prepared by in vitro transcription of recombinant pT7 Blue T-vector (Novagen Inc., Madison, WI) which contained iNOS cDNA. The sense

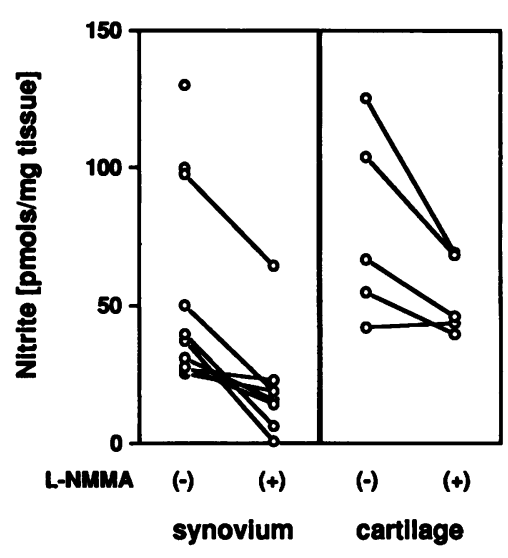

Figure 1. Ex vivo NO production by the synovium and the cartilage from RA patients and its inhibition by L-NMMA. $50 \mathrm{mg}$ synovium or cartilage was cultured for 24 $h$ in the presence or absence of $0.5 \mathrm{mM} \mathrm{L}$ NMMA. The nitrite concentration in the culture medium was quantified as described in Methods A significant inhibition by L-NMMA was found in NO production by rheumatoid synovium ( $P$ $<0.05$ ).

riboprobes were prepared likewise. Sections of the synovium were treated with $10 \mu \mathrm{g} / \mathrm{ml}$ proteinase $\mathrm{K}$ and hybridized with the labeled riboprobes. After hybridization, the specimens were treated with $20 \mu \mathrm{g} /$ $\mathrm{ml}$ RNase A. After intensive washing, probe binding was visualized with an alkaline phosphatase-conjugated anti-digoxigenin antibody (Boehringer Mannheim), 5-bromo-4-chloro-3-indolyl-phosphate, and 4nitroblue tetrazolium chloride.

cDNA synthesis and PCR amplification. Total RNA was prepared from the frozen samples and converted to CDNA as reported elsewhere (26). For the PCR assay, the cDNA was added to $20 \mathrm{pM}$ of sense and antisense primers, $1.25 \mathrm{mM} \mathrm{dNTPs}$, and $1 \mathrm{U}$ of Taq polymerase (Boehringer Mannheim) in the buffer as recommended by the manufacturer. The primers specific for iNOS were 5 '-CCATGGAACATCCCAAATAC-3' (sense) and 5'-TCTGCATGTACTTCATGAAGG-3' (antisense), and yielded 357-bp PCR products. The internal probe used for specific hybridization was 5'-GCTACAACATCCTGGAGGAA-3' (sense). The primers specific for $\beta$-actin were 5'-GTGGGGCGCCCCAGGCACCA-3' (sense) and 5'-CTCCTTAATGTCACGCACGATTTC-3' (antisense), and yielded 595-bp products. Its internal probe was $5^{\prime}$-CCACACCTTCTACAATGAGC-3' (sense). The amplification reaction for iNOS and $\beta$-actin consisted of 35 cycles at $94^{\circ} \mathrm{C}$ for $30 \mathrm{~s}$, $60^{\circ} \mathrm{C}$ for $30 \mathrm{~s}$, and $72^{\circ} \mathrm{C}$ for $1 \mathrm{~min}$ followed by final extension of $10 \mathrm{~min}$. The products were separated by agarose electrophoresis and visualized by ethidium bromide staining. The specificity of the amplified bands was validated by their predicted size and subsequent hybridization with the digoxigenin-labeled internal probes.

Sequencing of PCR products. The amplified iNOS fragments were purified from agarose gel. They were directly subcloned into pT7 Blue T-vector, which were then introduced into $E$. coli, NovaBlue cells (Novagen Corp.). The inserted iNOS genes were sequenced with dye-labeled primers and Ampli Taq DNA polymerase (Applied Biosystems Inc., Foster City, CA) by an automated DNA sequencing system (373A; Applied Biosystems Inc.).

In vitro synoviocyte and chondrocyte cultures. $10^{5}$ chondrocytes or $10^{6}$ synoviocytes were cultured in six-well plates (Costar Corp.) in 1 ml DME containing $10 \%$ FBS with no stimulator, $1 \mathrm{ng} / \mathrm{ml} \mathrm{IL-1} \beta$, or a combination of $1 \mathrm{ng} / \mathrm{ml} \mathrm{IL-} \beta, 10 \mathrm{U} / \mathrm{ml} \mathrm{TNF}-\alpha$, and $10 \mu \mathrm{g} / \mathrm{ml} \mathrm{LPS} \mathrm{for}$ $48 \mathrm{~h}$.

Statistical analysis. The statistical significance were evaluated by Wilcoxon signed rank test or linear regression analysis.

\section{Results}

NO production from ex vivo-cultured rheumatoid synovium and cartilage. We examined NO production from the inflamed synovium and cartilage. The conditioned media from ex vivocultured rheumatoid synovium and cartilage contained readily 

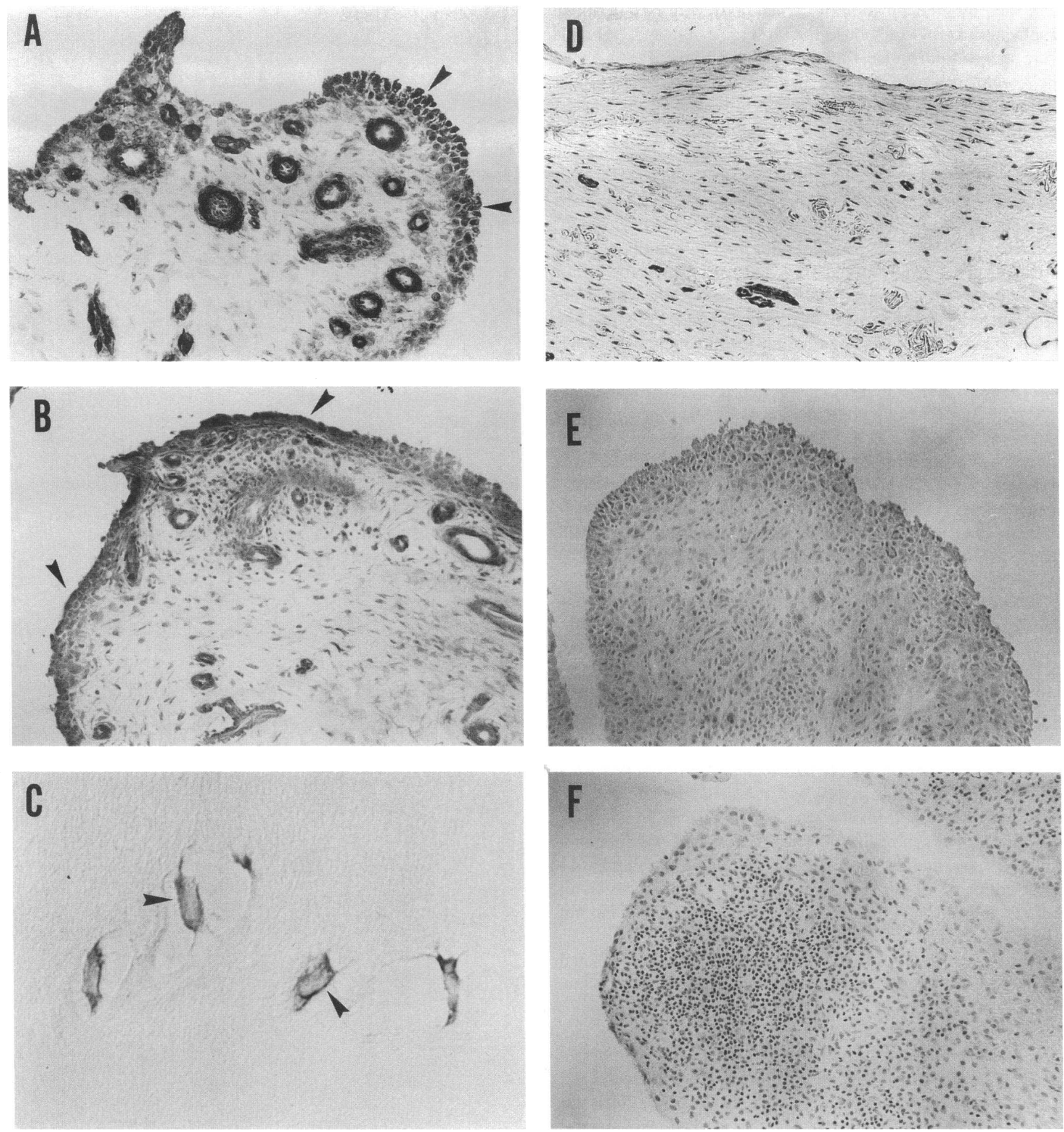

Figure 2. Immunohistochemical staining to identify the iNOS antigen in inflamed synovium and cartilage. $(A-C)$ Stained with anti-iNOS antiserum. $(A)$ Inflamed synovium from an RA patient; $(B)$ a synovium from an OA patient; $(C)$ cartilage from an RA patient. $(D)$ noninflamed synovium from a patient with trauma; $(E)$ stained with rabbit IgG for negative control; $(F)$ stained with anti-iNOS antiserum preabsorbed with iNOS antigen. The iNOS antigen was expressed in synovial lining cells ( $A$ and $B$, arrowheads), endothelial cells, and chondrocytes $(C$, arrowheads), and a part of infiltrating cells and fibroblasts. $(\times 100[A, B, C, D, E$, and $F]$ or $\times 200[C])$

detectable levels of the stable end products of NO release. In the presence of the specific NOS inhibitor, L-NMMA, NO production from rheumatoid synovium was significantly reduced $(P<0.05)$ (Fig. 1).

Immunohistochemical and in situ hybridization analyses of inflamed synovium. To define the cells producing NO in the inflamed synovium, 10 rheumatoid and 5 OA synovial sections were studied for iNOS protein and mRNA expression. Immunohistochemical studies of RA synovium with antiserum against iNOS revealed that iNOS protein was strongly expressed in synovial lining cells, endothelial cells, and, to a lesser extent, in the infiltrating mononuclear cells and synovial fibroblasts (Fig. $2 \mathrm{~A}$ ). iNOS was also detectable in cartilage obtained from the rheumatoid joints (Fig. $2 C$ ). The positive staining was 
abolished by preincubation of the antibody with $\mathrm{NH}_{2}$-terminal fragments (1-14) of mouse iNOS (Fig. $2 F$ ), and NO cells were stained with an isotype-matched rabbit IgG (Fig. $2 E$ ). In the specimens from five OA patients, although less cellular infiltration was observed, the iNOS positive cells were located in similar areas as in the rheumatoid synovium (Fig. $2 B$ ). In contrast, normal synovium expressed iNOS protein minimally in synovial lining cells and endothelial cells (Fig. $2 \mathrm{D}$ ). For characterization of the cells expressing iNOS, the specimens were stained with mAbs against CD2, CD14, CD20, HLA-DR, or Factor VIII. The cells reactive with the iNOS antibody were either positive for CD14 and HLA-DR, or positive for Factor VIII, and this was mutually exclusive. These $\mathrm{CD} 14^{+}$cells were large nuclear cells with oval-shaped nuclei. The cells reactive with CD2 or CD20 were negative for iNOS (data not shown).

In the in situ hybridization analysis, intense signals for iNOS mRNA were found in synovial lining cells, and endothelial cells in rheumatoid synovium. Scattered signals were present in infiltrating mononuclear cells (Fig. 3 A). An essentially similar pattern was seen in OA synovium, although the cellularity is less prominent (Fig. $3 \mathrm{~B}$ ). The distribution of iNOS mRNApositive cells was identical to that of iNOS protein-positive cells. In contrast, in the sections hybridized with sense iNOS cRNA probe, we could not detect any positive signals (Fig. $3 C$ ).

Western blot analysis of iNOS. Using the rabbit polyclonal antiserum to peptides 1-14 of mouse iNOS, Western blots identified $130-\mathrm{kD}$ bands, corresponding to the size of human iNOS protein in stimulated human chondrocytes and freshly isolated rheumatoid synoviocytes but not in nonstimulated human chondrocytes. No band was stained in rheumatoid synoviocytes with nonimmunized rabbit serum (Fig. 4).

Reverse transcriptase (RT)-PCR analysis of iNOS $m R N A$ expression. We studied iNOS and mRNA expression in the inflamed synovium from five RA patients, five OA patients, and four normal synovia by RT-PCR. iNOS and $\beta$-actin genes were amplified and Southern-blotted using labeled internal oligonucleotide probes of the corresponding gene (Fig. 5). In all of the inflamed synovium, iNOS mRNA was expressed but not in normal synovium.

The PCR products from rheumatoid synovium were isolated for nucleotide sequence analysis. All of 18 sequences determined were completely identical to the reported sequence of human chondrocyte iNOS (1214-1571) (27).

Correlation between the NO production and the proportion of $\mathrm{CDI}^{+}$cells in the synovium. The immunohistochemical and in situ hybridization analyses showed that $\mathrm{CD} 14^{+}$cells and iNOS $^{+}$cells had indentical distribution in rheumatoid synovium. Using synovia from eight RA patients, we studied the relationship between NO production and the proportion of $\mathrm{CD}^{+} 4^{+}$cells in the synovium. The fresh synoviocytes were isolated from the synovium, which were studied for NO production in ex vivo organ culture. They were incubated with FITClabeled anti-CD14/mAb. The positive cells were enumerated by a flow cytometer. Fig. 6 shows the relationship between the amounts of NO released into culture media and the presence of $\mathrm{CD}_{14}{ }^{+}$cells in corresponding synovium. The number of $\mathrm{CD}_{14}{ }^{+}$cells was positively correlated with the levels of NO production $(r=0.8, P<0.05)$.

In vitro NO production from synoviocytes and chondrocytes. We examined whether NO production from synoviocytes and chondrocytes can be regulated by inflammatory cytokines
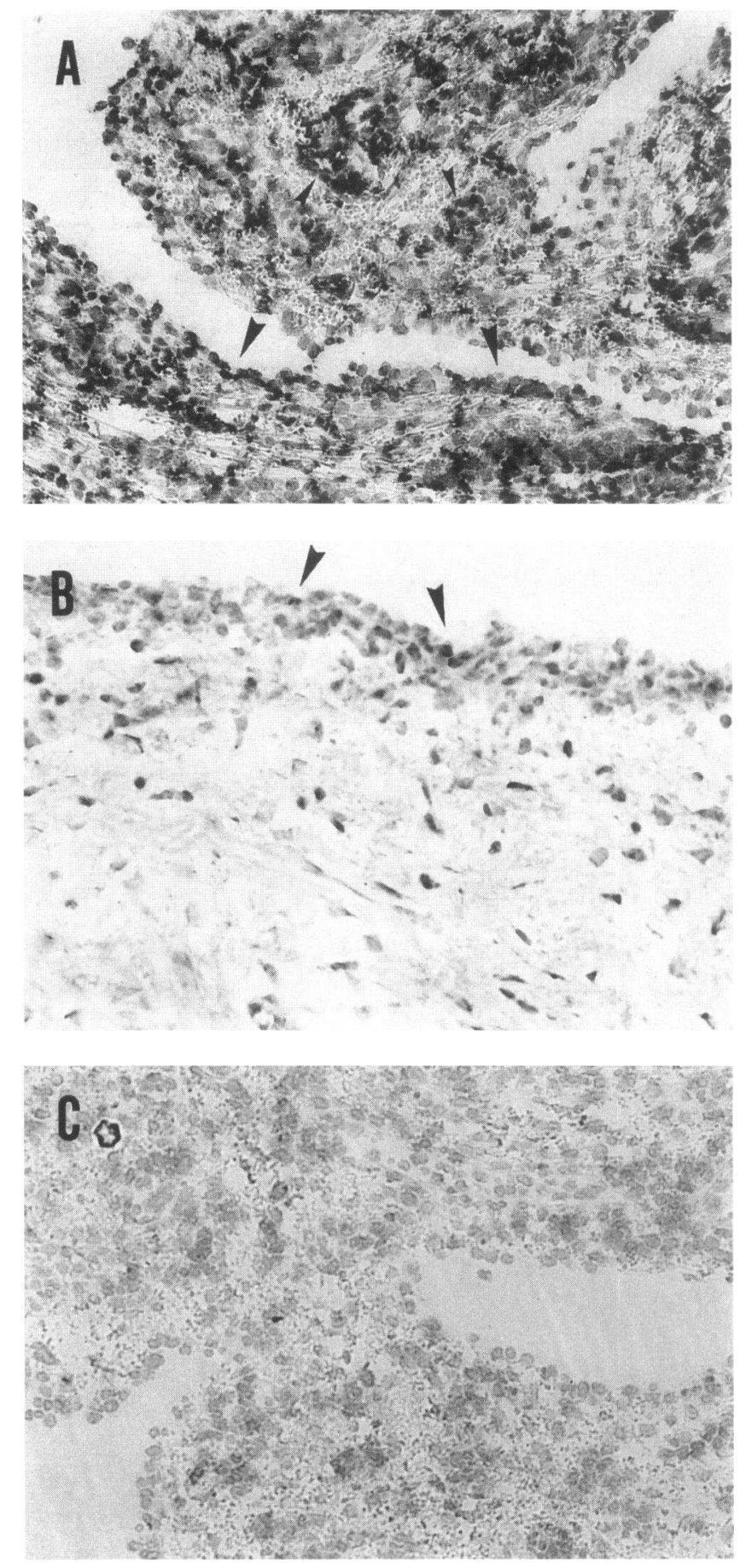

Figure 3. In situ hybridization of iNOS mRNA in RA $(A)$ and OA $(B)$ synovium probed with antisense riboprobes, and in RA synovium probed with sense riboprobes $(C)$. All samples were counterstained with methyl green. iNOS mRNA was detected in synovial lining cells ( $A$ and $B$,

large arrowheads), endothelial cells $(A$, small arrowheads $)$, and a part of infiltrating cells and fibroblasts. $(\times 200)$

present in arthritic joints. The synoviocytes and chondrocytes were freshly isolated from four RA patients. Fresh synoviocytes $\left(10^{6}\right.$ cells $)$ or chondrocytes $\left(10^{5}\right.$ cells $)$ were incubated alone,

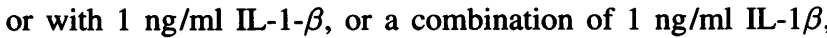
$10 \mathrm{U} / \mathrm{ml} \mathrm{TNF}-\alpha$, and $10 \mu \mathrm{g} / \mathrm{ml}$ LPS for $48 \mathrm{~h}$. NO production was upregulated in 7 out of 10 synovial samples. The NO pro- 


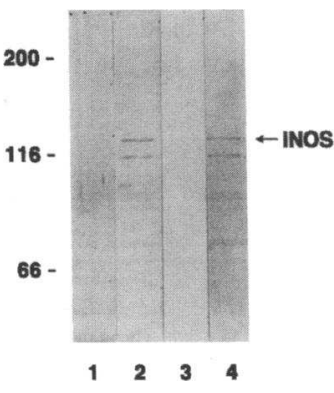

Figure 4. Western blot analysis of stimulated and nonstimulated human chondrocytes and rheumatoid synoviocytes. The cells were lysed and subjected to SDS-PAGE followed by immunoblot with a rabbit polyclonal anti-mouse iNOS $\mathrm{NH}_{2}$-terminal peptide (1-14), antiserum, or control serum. (Lane 1 ). Protein from nonstimulated chondrocytes stained with the antiserum. (Lane 2). Protein from chondrocytes stimulated with a combination of $1 \mathrm{ng} / \mathrm{m}$

IL- $1 \beta, 10 \mathrm{U} / \mathrm{ml} \mathrm{TNF}-\alpha$, and $10 \mu \mathrm{g} / \mathrm{ml} \mathrm{LPS} \mathrm{and} \mathrm{stained} \mathrm{with} \mathrm{antiserum.}$ (Lane 3). Protein from RA synoviocytes reacted with a nonimmunized rabbit control serum. (Lane 4). protein from RA synoviocytes stained with the antiserum. Molecular markers $(\mathrm{kD})$ are shown on the left. An arrow indicates $130-\mathrm{kD}$ protein bands.

duction from both synoviocytes and chondrocytes was increased 2.5 -fold after stimulation with a combination of IL- $1 \beta$, TNF$\alpha$, and LPS (Fig. 7). We also examined the NO production from synovial fibroblast cell lines derived from RA synovium, with or without the same stimuli. The synovial fibroblasts did not produce NO even after stimulation (data not shown).

\section{Discussion}

We have demonstrated that NO in human inflammatory arthritides derives from the cells in both synovium and cartilage. Farrell et al. (19) previously showed increased concentrations of nitrite in synovial fluids and sera from RA and OA patients, which agrees with our preliminary observations that nitrite/ nitrate concentrations were increased in RA and OA synovial fluids.

The nitrite production from ex vivo-cultured rheumatoid synovium and cartilage was readily detectable. The results indicated that accumulated nitrite/nitrate in rheumatoid synovial fluids derived from both rheumatoid synovium and cartilage. The specific NOS inhibitor, L-NMMA, reduced nitrite production from both tissues. The inhibition was not complete, compared with the inhibition that was achievable in isolated cell culture. We speculate that the residual nitrite production was due to NO generated by cells deep in the tissues because they could produce NO before the inhibitor penetrated the tissues.

Both the immunohistochemical and in situ hybridization studies in inflammatory arthritides have shown that iNOS mRNA and protein were expressed in synovial lining cells,

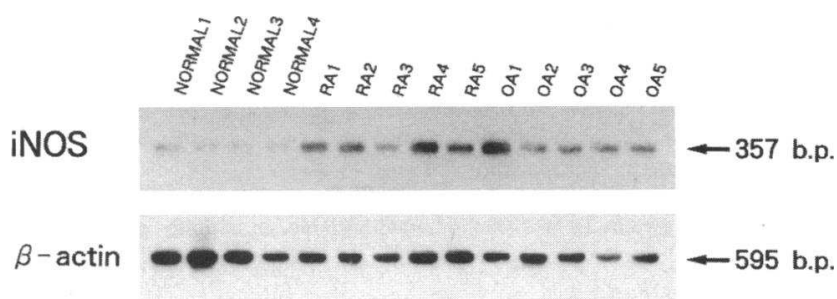

Figure 5. Southern blot hybridization of iNOS RT-PCR products amplified from synovium of RA and OA patients. (Lane 1-4). Noninflamed synovia from patients with trauma; lanes 5-9, RA synovium; (lanes 10-14) OA synovium. The iNOS mRNA were increased in inflamed synovium compared with noninflamed synovium.

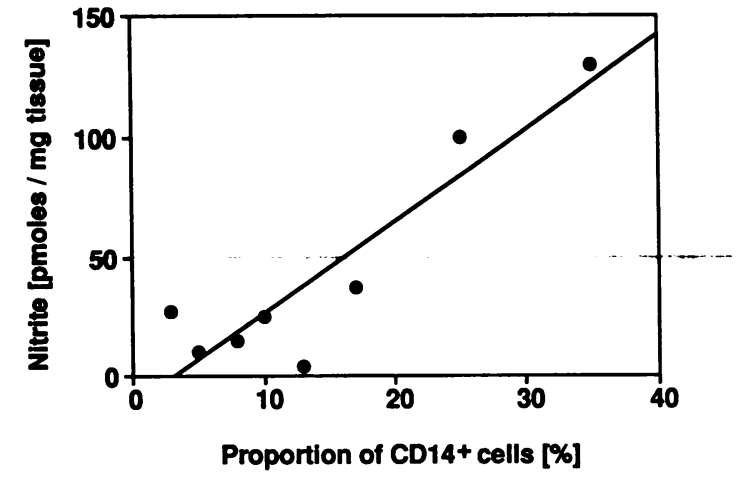

Figure 6. Relationship between NO production and the proportion of $\mathrm{CD}_{14}{ }^{+}$cells in rheumatoid synovium. A significant positive correlation was found ( $r=0.8, P<0.05$ ). The $\mathrm{x}$-axis represents the proportion of $\mathrm{CD}_{1} 4^{+}$cells, and the $\mathrm{y}$-axis represents the NO production.

endothelial cells, and to a lesser extent, in infiltrating cells and synovial fibroblasts. Western blot analysis of rheumatoid synoviocytes and stimulated human chondrocytes showed that the specific antiserum reacted to a $130-\mathrm{kD}$ band protein corresponding to the human iNOS protein. There was an additional 115$\mathrm{kD}$ protein reactive with the specific antiserum. The size was different from that of constitutive NOS protein (135 kD), and we speculate that it is a degradation product of iNOS because this band appeared in parallel with the $130-\mathrm{kD}$ band. In addition, the nucleotide sequences of the PCR products obtained in the iNOS mRNA RT-PCR assay of rheumatoid synovium were completely identical to that of human chondrocyte iNOS.

In immunohistochemical staining, $\mathrm{CD}_{14}{ }^{+}$and $\mathrm{HLA}-\mathrm{DR}^{+}$ cells displayed the same distribution as iNOS $^{+}$cells. Morphology of the iNOS $^{+}$cells and the $\mathrm{CD}_{14}{ }^{+}$cells was compatible with that of macrophages. These data suggested that the NOproducing synoviocytes belong to type A synoviocytes, derived from monocytes. In addition, the positive correlation of the NO production with $\mathrm{CD} 14^{+}$cell proportion in the inflammatory synovium implies the $\mathrm{CD} 14^{+}$cells are a primary source of NO from the synovium, compared with endothelial cells. Of note, iNOS-positive cells were also seen in OA synovium, although its extent was less remarkable. According to the semiquantitative RT-PCR analysis, iNOS mRNA expression in OA synovium was comparable to that in rheumatoid synovium. These

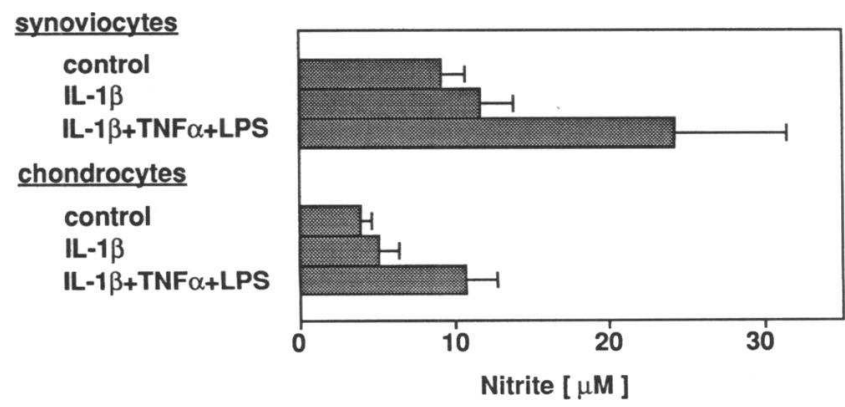

Figure 7. NO production from isolated rheumatoid synoviocytes and cultured chondrocytes in the presence of $\mathrm{IL}-1 \beta$ alone or a combination of IL- $1 \beta$, TNF- $\alpha$, and LPS for $48 \mathrm{~h}$. The nitrite in the media increased in 2.5 -fold by stimulation with a combination of the IL- $1 \beta$, TNF- $\alpha$, and LPS. Data are shown as means \pm SD from triplicate wells. 
results suggested that iNOS expression is up-regulated in inflammatory synovium.

We do not classify OA as an inflammatory disease. However, it was noted that the $\mathrm{OA}$ joints have slight to moderate inflammatory changes in limited areas of the synovium (28). We observed iNOS ${ }^{+}$cells in such areas and assumed that they were the source of iNOS mRNA detected with the semiquantitative PCR analysis.

The significance of NO synthesis in rodent macrophages has been well established, although it is not certain whether an analogy can be extended to human monocytes/macrophages. Thus far, there are several evidences for human monocytes/ macrophages to synthesize NO. Human macrophages exposed to TNF- $\alpha$, GM-CSF, and selected avirulent strains of Mycobacterium avium produce NO (29). Pulmonary alveolar macrophages activated by Pneumocystis carinii are also shown to elaborate NO (30). However, expression and regulation of iNOS in human monocytes/macrophages has remained unknown, and high output NO production from human macrophages has not been observed. Our data showed that human $\mathrm{CD}_{14}{ }^{+}$cells expressed iNOS and produced NO in inflammatory synovium. Thus, it is likely that human monocytes/macrophages produce NO in selective situations, perhaps in response to most complete stimuli.

Bacterial products and various inflammatory cytokines, such as LPS, IL-1, TNF- $\alpha$, and IFN- $\gamma$, were shown to induce NO from various cells $(2-5,31)$. Combinations of two or three of TNF- $\alpha$, IL-1, IFN- $\gamma$, and LPS synergestically stimulated rodent macrophage and hepatocyte NO production $(2,32)$. The cytokines or LPS induced NO production by rodent and human chondrocytes isolated from noninflamed cartilage was also reported by Stadler et al. and Palmer et al. $(22,33)$. In the present study, we showed that a combination of IL- $1 \beta$, TNF- $\alpha$, and LPS increased NO production by synoviocytes and chondrocytes isolated from RA. Rediske et al. (34) previously demonstrated that NO production by chondrocytes isolated from noninflamed human cartilage was dramatically up-regulated by addition of IL-1. We did not see an equivalent increase of NO production by IL-1. However, basal levels of NO production from RA chondrocytes were higher than those from noninflamed cartilage. It is possible that NO production of chondrocytes from RA were already accelerated by in vivo stimulation and less responsive to additional stimuli. Various cytokines derived from macrophages and/or fibroblasts, such as IL-1, IL-6, TNF- $\alpha$, and GM-CSF are present in the rheumatoid synovial fluid and synovium (13-16, 35-37). These findings suggest that inflammatory cytokines contribute to the upregulation of NO production in inflamed joints.

We observed that cytokines plus LPS induced up-regulation of NO production in 7 out of 10 synovial samples. The exact reason for the presence of nonresponders is unknown. We speculate that nonresponding cells were already exhausted by in vivo stimulation or the tissues might contain cells that produced suppressive molecules against NO induction when stimulated $(38-40)$.

The synovial fibroblast cell lines established from RA synovium were not NO producers. Stimulation with the inflammatory cytokines and LPS failed to induce NO production. This finding agrees with a recent report by Rediske et al. (34). Since the synovial fibroblasts do not express $\mathrm{CD} 14$, the data support our observation that most of the NO-producing synoviocytes are $\mathrm{CD} 14^{+}$.
Possible proinflammatory effects of NO include augmentation of vascular permeability in inflamed tissues (41), the generation of destructive free radicals such as peroxynitrite and hydroxyl radical (41-44), and the induction of the inflammatory cytokines like TNF- $\alpha$ and IL-1. $(45,46)$. A recent study by Leibovich et al. (47) has demonstrated that NO is involved in the production of angiogenic activity by human LPS-stimulated monocytes.

NO was originally identified as the endothelium-derived relaxing factor, which regulates vascular tone. We recently reported increased levels of endothelin-1, which is a potent vasoconstrictor, in inflammatory arthritides (48). It was intriguing to find that both vasoconstrictive and vasodilative substances are upregulated in the inflammatory synovium.

We introduce NO as a new member of the factors that are overexpressed and regulated by inflammatory cytokines in human inflamed joints. It may be a pathogenetic mediator of connective tissue destruction in arthritides.

\section{Acknowledgments}

We thank Junpei Haruta for excellent technical assistance and Shunichi Murakami for his help collecting clinical samples. We are also grateful to Dr. Martin Lotz for his critical reading of the manuscript.

This work was supported in part by a grant from the Ministry of Education, Science, and Culture of Japan. Hiroshi Sakurai was partly supported by KANEK A Corporation.

\section{References}

1. Nathan, C. 1992. Nitric oxide as a secretory product of mammalian cells. FASEB (Fed. Am. Soc. Exp. Biol.) J. 6:3051-3064.

2. Geller, D. A., A. K. Nussler, M. D. Silvio, C. J. Lowenstein, R. A. Shapiro, S. C. Wang, R. L. Simmons, and T. R. Billiar. 1993. Cytokines, endotoxin and glucocorticoids regulate the expression of inducible nitric oxide synthase in hepatocytes. Proc. Natl. Acad. Sci. USA. 90:522-526.

3. Kanno, K., Y. Hirata, T. Imai, and F. Marumo. 1993. Induction of nitric oxide synthase gene by interleukin in vascular smooth muscle cells. Hypertension (Dallas). 22:34-39.

4. Nakayama, D. K., D. A. Geller, C. J. Lowenstein, H. D. Chern, P. Davies, B. R. Pitt, R. L. Simmons, and T. R. Billiar. 1992. Cytokines and lipopolysaccharide induce nitric oxide synthase in cultured rat pulmonary artery smooth muscle. Am. J. Respir. Cell Mol. Biol. 7:471-476.

5. Curran, R. D., T. R. Billiar, D. J. Stuehr, K. Hofmann, and R. L. Simmons. 1989. Hepatocytes produce nitrogen oxides from $L$-arginine in response to inflammatory products of Kupffer cells. J. Exp. Med. 170:1769-1774.

6. MacMicking, J. D., D. O. Willenborg, M. J. Weidemann, K. A. Rockett, and W. B. Cowden. 1992. Elevated secretion of reactive nitrogen and oxygen intermediates by inflammatory leukocytes in hyperacute experimental autoimmune encephalomyelitis: enhancement by the soluble products of encephalitogenic T cells. J. Exp. Med. 176:303-307.

7. Langrehr, J. M., N. Murase, P. M. Markus, X. Cai, P. Neuhaus, W. Schraut, R. L. Simmons, and R. A. Hoffman. 1992. Nitric oxide production in host-versusgraft and graft-versus-host reactions in the rat. J. Clin. Invest. 90:679-683.

8. Koprowski, H., Y. M. Zheng, E. Heber-Katz, N. Fraser, L. Rorke, Z. F. Fu, C. Hanlon, and B. Dietzschold. 1993. In vivo expression of inducible nitric oxide synthase in experimentally induced neurologic diseases. Proc. Natl. Acad. Sci. USA. 90:3024-3027.

9. McCartney-Francis, N., J. B. Allen, D. E. Mizel, J. E. Albina, Q. W. Xie, C. F. Nathan, and S. M. Wahl. 1993. Suppression of arthritis by an inhibitor of nitric oxide synthase. J. Exp. Med. 178:749-754.

10. Stefanovic-Racic, M., K. Meyers, C. Meschter, J. W. Coffey, R. A. Hoffman, and C. H. Evans. 1994. N-monomethyl arginine, an inhibitor of nitric oxide synthase, suppresses the development of adjuvant arthritis in rats. Arthritis Rheum. 37:1062-1069.

11. Weinberg, J. B., D. L. Granger, D. S. Pisetsky, M. F. Seldin, M. A. Misukonis, S. N. Mason, A. M. Pippen, P. Ruiz, E. R. Wood, and G. S. Gilkeson. 1994. The role of nitric oxide in the pathogenesis of spontaneous murine autoimmune disease: increased nitric oxide production and nitric oxide synthase expression in MRL-lpr/lpr mice, and reduction of spontaneous glomerulonephritis and arthritis by orally administered $N^{\mathrm{G}}$-monomethyl-L-arginine. J. Exp. Med. 179:651-660. 
12. Ziff, M. 1989. Pathways of mononuclear cell infiltration in theumatoid synovitis. Rheumatol. Int. 9:97-103.

13. Firestein, G. S., J. M. Alvaro-Gracia, and R. Maki. 1990. Quantitative analysis of cytokine gene expression in rheumatoid arthritis. J. Immunol. 144:3347-3353.

14. Bergroth, V., N. J. Zvaifler, and G. S. Firestein. 1989. Cytokines in chronic inflammatory arthritis. III. Rheumatoid arthritis monocytes are not unusually sensitive to $\gamma$-interferon, but have defective $\gamma$-interferon-mediated HLA-DQ and HLA-DR induction. Arthritis Rheum. 32:1074-1079.

15. Hirano, T., T. Matsuda, M. Turner, N. Miyasaka, G. Buchan, B. Tang, K Sato, M. Simizu, R. Maini, M. Feldmann, and T. Kishimoto. 1988. Excessive production of interleukin 6/B cell stimulatory factor- 2 in rheumatoid arthritis. Eur. J. Immunol. 18:1797-1801.

16. Miyasaka, N., K. Sato, M. Goto, M. Sasano, M. Natsuyama, K. Inoue, and K. Nishioka. 1988. Augmented interleukin-1 production and HLA-DR expression in the synovium of rheumatoid arthritis patients. Arthritis Rheum. 31:480486.

17. Farahat, M. N., G. Yanni, R. Poston, and G. S. Panayi. 1993. Cytokine expression in synovial membranes of patients with rheumatoid arthritis and osteoarthritis. Ann. Rheum. Dis. 52:870-875.

18. Hamerman, D. 1989. The biology of osteoarthritis. N. Engl. J. Med. 320:1322-1330.

19. Farrell, A. J., D. R. Blake, R. M. Palmer, and S. Moncada. 1992. Increased concentrations of nitrite in synovial fluid and serum samples suggest increased nitric oxide synthesis in rheumatic diseases. Ann. Rheum. Dis. 51:1219-1222.

20. Arnett, F. C., S. M. Edworthy, D. A. Bloch, D. J. McShane, J. F. Fries, N. S. Cooper, L. A. Healey, S. R. Kaplan, M. H. Liang, H. S. Luthra, et al. 1988. The American Rheumatism Association 1987 revised criteria for the classification of rheumatoid arthritis. Arthritis Rheum. 31:315-324.

21. Ding, A. H., C. F. Nathan, and D. J. Stuehr. 1988. Release of reactive nitrogen intermediates and reactive oxygen intermediates from mouse peritoneal macrophages. Comparison of activating cytokines and evidence for independent production. J. Immunol. 141:2407-2413.

22. Palmer, R. M. J., M. S. Hickery, I. G. Charles, S. Moncada, and M. T. Bayliss. 1993. Induction of nitric oxide synthase in human chondrocytes. Biochem. Biophys. Res. Commun. 191:398-405.

23. Tsujino, M., Y. Hirata, T. Imai, K. Kanno, S. Eguchi, H. Ito, and F. Marumo. 1994. Induction of nitric oxide synthase gene by interleukin- $\beta$ in cultured rat cardiocytes. Circulation. 90:375-383.

24. Miyasaka, N., K. Sato, K. Yamamoto, M. Goto, and K. Nishioka. 1989. Immunological and immunohistochemical analysis of rheumatoid nodules. Ann. Rheum. Dis. 48:220-226.

25. McCachren, S. S. 1991. Expression of metalloproteinases and metalloproteinase inhibitor in human arthritic synovium. Arthritis Rheum. 34:1085-1093.

26. Saito, I., B. Servenius, T. Compton, and R. I. Fox. 1989. Detection of Epstein-Barr virus DNA by polymerase chain reaction in blood and tissue biopsies from patients with Sjögren's syndrome. J. Exp. Med. 169:2191-2198.

27. Charles, I. G., R. M. J. Palmer, M. S. Hickery, M. T. Bayliss, A. P. Chubb, V. S. Hall, D. W. Moss, and S. Moncada. 1993. Cloning, characterization, and expression of a cDNA encoding an inducible nitric oxide synthase from the human chondrocytes. Proc. Natl. Acad. Sci. USA. 90:11419-11423.

28. Gordon, G. V., T. Villanueva, H. R. Schumacher, and V. Gohel. 1984 Autopsy study correlating degree of osteoarthritis, synovitis and evidence of articular calcification. J. Rheum. 11:681-686.

29. Denis, M. 1991. Tumor necrosis factor and granulocyte macrophagecolony stimulating factor stimulate human macrophages to restrict growth of virulent Mycobacterium avium and to kill avirulent $M$. avium:killing effector mechanism depends on the generation of reactive nitrogen intermediates. J. Leuko cyte Biol. 49:380-387.

30. Sherman, M. P., M. L. Loro, V. Z. Wong, and D. P. Tashkin. 1991 Cytokine- and Pneumocystis carinii-induced L-arginine oxidation by murine and human pulmonary alveolar macrophages. J. Protozool. 38:234-236.

31. Stuehr, D. J., and M. A. Marletta. 1985. Mammalian nitrate biosynthesis mouse macrophages produce nitrite and nitrate in response to Escherichia coli lipopolysaccharide. Proc. Natl. Acad. Sci. USA. 82:7738-7742.

32. Stuehr, D. J., and M. A. Marletta. 1987. Synthesis of nitrite and nitrate in murine macrophage cell lines. Cancer Res. 47:5590-5594.

33. Stadler, J., M. Stefanovic-Racic, T. R. Billiar, R. D. Curran, L. A. McIntyre, H. I. Georgescu, R. L. Simmons, and C. H. Evans. 1991. Articular chondrocytes synthesize nitric oxide in response to cytokines and lipopolysaccharide. $J$. Immunol. 147:3915-3920.

34. Rediske, J. J., C. F. Koehne, B. Zhang, and M. Lotz. 1994. The inducible production of nitric oxide by articular cell types. Osteoarthritis Cart. 2:199-206.

35. Lotz, M., T. Moats, and P. M. Villiger. 1992. Leukemia inhibitory factor is expressed in cartilage and synovium and can contribute to the pathogenesis of arthritis. J. Clin. Invest. 90:888-896.

36. Lotz, M. J. Kekow, and D. A. Carson. 1990. Transforming growth factor$\beta$ and cellular immune responses in synovial fluids. J. Immunol. 144:4189-4194.

37. Villiger, P. M., R. Terkeltaub, and M. Lotz. 1992. Production of monocyte chemoattractant protein-1 by inflamed synovial tissue and cultured synoviocytes J. Immunol. 149:722-727.

38. Ding, A., C. F. Nathan, J. Graycar, R. Derynck, D. J. Stuehr, and S. Srimal. 1990. Macrophage deactivating factor and transforming growth factors$\beta 1,-\beta 2$, and $-\beta 3$ inhibit induction of macrophage nitrogen oxide synthesis by IFN- $\gamma$. J. Immunol. 145:940-944.

39. Bogdan, C., Y. Vodovotz, J. Paik, Q. W. Xie, and C. Nathan. 1994 Mechanism of suppression of nitric oxide synthase expression by interleukin-4 in primary mouse macrophages. J. Leukocyte Biol. 55:227-233.

40. Cunha, F. Q., S. Moncada, and F. Y. Liew. 1992. Interleukin-10 (IL10 ) inhibits the induction of nitric oxide synthase by interferon- $\gamma$ in murine macrophages. Biochem. Biophys. Res. Commun. 182:1155-1159.

41. Mayhan, W. G. 1992. Role of nitric oxide in modulating permeability of hamster cheek pouch in response to adenosine 5 '-diphosphate and bradykinin. Inf lammation. 16:295-305

42. Beckman, J. S., T. W. Beckman, J. Chen, P. A. Marshall, and B. A Freeman. 1990. Apparent hydroxyl radical production by peroxynitrite: implications for endothelial injury from nitric oxide and superoxide. Proc. Natl. Acad. Sci. USA. 87:1620-1624.

43. Ischiropoulos, H., L. Zhu, and J. S. Beckman. 1992. Peroxynitrite formation from macrophage-derived nitric oxide. Arch. Biochem. Biophys. 298:446 451.

44. Zhu, L., C. Gunn, and J. S. Backman. 1992. Bactericidal activity of peroxynitrite. Arch. Biochem. Biophys. 298:452-457.

45. Lander, H. M., P. Sehajpal, D. M. Levine, and A. Novogrodsky. 1993. Activation of human peripheral blood mononuclear cells by nitric oxide-generating compounds. J. Immunol. 150:1509-1516.

46. Magrinat, G., S. N. Mason, P. S. Shami, and J. B. Weinberg. 1992. Nitric oxide modulation of human leukemia cell differentiation and gene expression. Blood. 80:1880-1884.

47. Leibovich, S. J., P. J. Polverini, T. W. Fong, L. A. Harlow, and A. E. Koch. 1994. Production of angiogenic activity by human monocytes requires an L-arginine/nitric oxide-synthase-dependent effector mechanism. Proc. Natl. Acad. Sci. USA. 91:4190-4194.

48. Miyasaka, N., Y. Hirata, K. Ando, K. Sato, H. Morita, M. Shichiri, K Kanno, K. Tomita, and F. Marumo. 1992. Increased production of endothelin-1 in patients with inflammatory arthritides. Arthritis Rheum. 35:397-400. 